\title{
Extending Economic Analysis to \\ Analyze Policy Issues More Broadly
}

Yew-Kwang NG

2016

EGC Report No: 2016/09

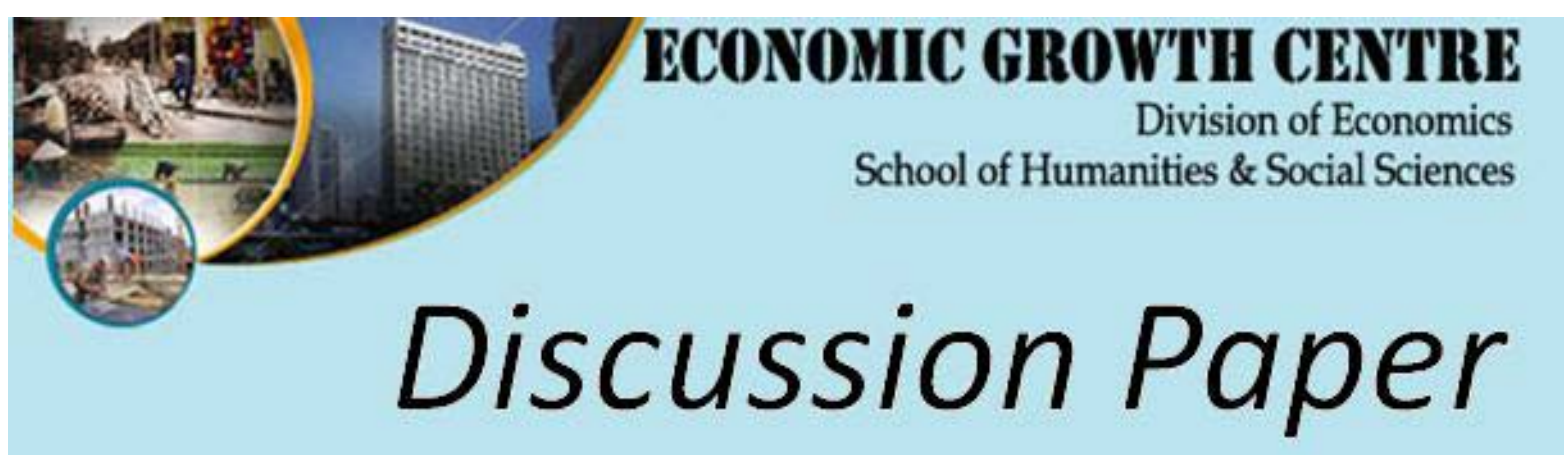


The author(s) bear sole responsibility for this paper.

Views expressed in this paper are those of the author(s) and not necessarily those of the Economic Growth Centre, NTU. 


\title{
Extending Economic Analysis to Analyze Policy Issues More Broadly [A paper based on a keynote address presented at WEAI conference, 2016; see:
}

\author{
http://www.weai.org/PR2016 ] \\ Yew-Kwang NG \\ Winsemius Professor, Division of Economics, \\ Nanyang Technological University, Singapore 637332. \\ Email: ykng@ntu.edu.sg
}

\begin{abstract}
Extending traditional economic policy analysis to include factors emphasized by other social scientists and philosophers, more social and public policy issues may be analyzed more adequately. For example, should the market expand beyond its traditional confines of goods and services? Should more immigration be allowed? Wider effects like social harmony, repugnance and morality should also be considered. Though the extended analysis does not provide a definite general answer, in combination with the first theorem of welfare economics and the principle of treating a dollar as a dollar in specific issues, it provides some general propositions that guide the analysis of relevant costs and benefits of specific policy changes beyond narrow economic efficiency.
\end{abstract}

\section{Disclosure/Acknowledgment}

The author confirms no conflict of interest and wishes to thank Nanyang Technological University for general research support and to Zhang CHEN and Yan WANG for research assistance.

Keywords: Economic analysis; public policy; political economy; economics imperialism; markets; morals.

JEL Codes: H Public Economics; D6 Welfare Economics; A120 Relation of Economics to Other Disciplines. 
Largely following Mäki (2009), we may distinguish between economic imperialism and economics imperialism. The former describes the expansion of the economic way of doing things (monetary transaction, exchange, prices and markets) beyond its traditional confines of material goods and services to other spheres of the society. The manifestation of this expansion includes diverse activities like paying your child to study or to mow the lawn, paying someone to line up for you, paying for blood donation, organ donation, surrogate motherhood, prostitution, etc. The communitarians (e.g. Anderson 1993, Sandel 2012, 2013) deplore this expansion as threatening to turn a market economy into a market society. ${ }^{\mathrm{i}}$ On the other hand, economics imperialism describes the expansion of economic analysis into other areas of social sciences like marriage, family, having children, racial discrimination, laws, politics, etc., as pioneered by Gary Becker (1957 on discrimination, 1978 on behavior, 1981 on family), Anthony Downs (1957 on democracy), Buchanan \& Tullock (1962 on political decisions), Olson (1965 on collective action), etc. While these forerunners typically assumed perfect markets, and just applied core economic analysis of rational constrained maximization to other areas, newer versions (e.g. Fine \& Milonakis 2009) recognize and tackle market imperfections. 'Economic imperialism' may also be taken as the conquest of other nations by economic means or for economic purposes. However, this is not the concern of this paper. Instead, this paper attempts to make a small generalization along the line of economics imperialism and apply the generalized method to analyze some issues of economic imperialism, in particular, on whether the expansion of the market is desirable.

In the words of Stigler (1984, p.311), economists have been 'aggressive in addressing central problems in ... neighboring social disciplines ... without any invitations'. This economics imperialism has made very significant impact. It has been supported (e.g. Hirshleifer 1985, Lazear 2000), opposed (e.g. Coase 1978, Fine 2002), and analyzed (e.g. Mäki 2009). 'What gives economics its imperialist invasive power is that our analytic categories-scarcity, cost, preferences, opportunities, etc.-are truly universal in applicability. Even more important is our structured organization of these concepts into the distinct yet intertwined processes of optimization on the individual decision level and equilibrium on the social level of analysis' (Hirshleifer 1985, p.53). To this important observation we may add that, in all social sciences, especially where public policy is concerned, a crucially important issue is how decisions are made at the individual and collective levels and how these act and interact to ultimately affect the 
welfare of people which is of ultimate value. Economics is particularly suitable for such analysis, but some extensions may be desirable. While the expansion of economic analysis to more social issues may be regarded as economics imperialism, the extension to incorporate factors such as altruism, fairness, and morality may also be regarded as reverse imperialism, the conquest of traditionally non-economic concepts from other social sciences into the hard-core of economic analysis. Thus, instead of speaking of imperialism, perhaps unification and pluralism may be better descriptions. ${ }^{\text {ii }}$

\section{Analysis}

Since most if not all public policy issues, economic, political, sociological and beyond, are, directly or indirectly, concerned with the well-being of individuals in the society, the economists' concepts of individual utility, social welfare and their methods of analyzing them may be usefully applied to analyze issues beyond the traditional concern of economics to cover many if not largely all social issues, whether within the traditional confines of economics or not. It is true that much of social sciences are concerned with the more objective/positive issues of things like social processes and changes without necessarily investigating their effects on individual well-being. However, even fundamental knowledge in either maths/logics, natural sciences, or social sciences may be useful, perhaps after many steps of application. Thus, the construction of bridges needs engineering knowledge which is based on physics and so on. The pursuit of fundamental research and pure science should certainly be encouraged. However, ultimately speaking, bearing fruits is more important than shedding lights, as Pigou (1922) put it, though light shedding will most certainly lead to fruit bearing at some stage. This is particularly true for social sciences.

Fruit bearing may include literally fruits like apples and pears, but also other economic products and beyond, including social harmony, peace, freedom, love, etc. What may be included in this wider sense of fruits depends on the ultimate objective of individuals. (For simplicity, we focus on human individuals and ignore issues like animal welfare on which see Ng 1995, 2016.) Rationally, ignoring the effects on others (accounting for that may involve double counting if not careful), the ultimate objective of an individual is her welfare, well-being, or happiness (Benjamin 2012, Ng 2013, ch. 2). Given the time period and ignoring the degree of formality, these three terms are just different descriptions of the same thing, at least in 
accordance to the definitions adopted here. Thus, provided we have not ignored effects on others and in the future, we may use welfare as the ultimate fruit.

For the level of individuals, economists usually use the concept of utility instead of welfare. In modern economics, the utility of an individual just represents her preference such that (i) Individual i prefers $\mathrm{x}$ to $\mathrm{y}$; and (2) The utility level of individual i at $\mathrm{x}$ is higher than at $\mathrm{y}$, are taken to be the same thing. With preference referring only to ordinal ranking, then the relevant utility function is said to be ordinal and subject to any increasing transformation. As long as a higher indifference curve carries a higher utility number, how much higher is not relevant. Whatever the cardinal utility numbers (with ordering unchanged), the same set of indifference curves will yield the same demand functions for goods (subsumed services). Economists concerned only with positive theories of production and consumption may thus ignore the cardinal intensities of preferences. However, for policy choices beyond what may be judged by the Pareto principle or for changes that make some individuals better off and some worse off, interpersonal comparisons of cardinal utilities are needed to make reasonable decisions (Mueller 2003, ch.23). Since this paper is not just concerned with the positive theories of production and consumption, but with public policy, intensities of preferences are not abstracted away.

The preference of an individual may differ from her welfare due to ignorance or imperfect knowledge/foresight, to a concern for the welfare of others over-and-above the effects on one's own welfare (like the warm-glow effect), or to irrational preferences (Ng 1999). For simplicity, these divergences between individual preference (utility) and welfare will be ignored here as raising different sorts of issues. Thus, to be more distinct from social welfare, we will use 'utility' instead of 'welfare'. This leads us to the question: How should individual utilities be aggregated into social welfare. Though I have argued for a utilitarian SWF (social welfare

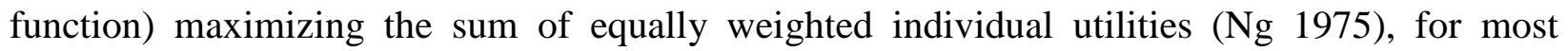
purposes here, a welfarist SWF (in Eq. 1 below) observing the Pareto principle (social welfare W being an increasing function of all individual utilities), as accepted by most economists and consequentialist philosophers and social scientists, will be sufficient.

$$
\mathrm{W}=\mathrm{W}\left(\mathrm{U}^{1}, \mathrm{U}^{2}, \ldots, \mathrm{U}^{\mathrm{I}}\right) ; \partial \mathrm{W} / \partial \mathrm{U}^{\mathrm{i}}>0 \text { for all } \mathrm{i} .
$$

A welfarist SWF as in (1) may violate some deontological rules like the categorical imperatives of Kant or the constitutional constraints of a country. First, it may be argued that, provided effects on others and in the future are adequately taken into account, there is no need to 
take account of non-welfare factors/rules (Ng 1990). Rules (including moral principles, legal laws and constitutions) are taken as useful precisely for the promotion of long-term overall welfare. Why have some rules but not others? The choice must be based on some considerations; for the society as a whole, long-term social welfare is the most acceptable one. Secondly, for the strict Kantians, they may regard our analysis as only valid within the scope where the compelling deontic rules are not violated. Since individual utilities may still differ due to changes in economic and social factors without affecting any deontic rules or constitutional constraints, our analysis is still of some relevance, though somewhat limited, being subject to the non-violation of these rules. Alternatively, the Kantians may take our framework of analysis but regard the violation of certain categorical imperatives as meaning a huge reduction in general morality $\mathrm{M}$ that will certainly be unacceptable (or will hugely reduce social welfare).

In either case, we may proceed on the understanding that, at least for the important part of fruit bearing, all social sciences are interested in effects on social welfare through individual utilities. Then, the basic framework of economics, its welfare analysis in particular, is applicable (applicability does not imply completeness) to all social sciences, except that what enter individual utility functions should be much broader, not being confined to the traditional economic factors of goods and services only. At least to some extent, this has been accepted or used in the imperialistic conquests of economics. For example, the most important figure in economic imperialism, Gary Becker (1992, p. 38) said at the beginning of his Nobel lecture: 'I have tried to pry economists away from narrow assumptions about self interest. Behavior is driven by a much richer set of values and preferences'. However, instead of applying economics imperialism on specific issues (as done with great successes by Becker and his followers), this paper attempts to obtain some general results (generality does not imply exhaustiveness). In particular, we wish to show that some useful propositions may be derived from some compelling axioms.

Axiom 1: The utility level of an individual may be affected by the activities of other individuals.

An individual may seclude herself from the society and lives perhaps in the mountain. Even such a secluded individual may be affected by the activities of others through say climate change. This axiom is thus compelling. Obviously, an individual is affected by the activities of others which may include those generating pollution and outright illegal ones. 
Axiom 2: The prevailing morality in a society may affect the utility levels of individuals in the society.

This axiom is not only compelling, it also represents a concession by an economist to the communitarians on the importance of morality. It is clearly acceptable especially to the communitarians. That it is compelling even to economists can be seen by noting that no economists deny the existence of social interaction in a wide sense beyond market exchange. Even on your way to the supermarket, you may be affected by the behavior of people you encounter, including whether they are polite and friendly, whether they rob you, etc. At least to some extent, their behavior is affected by their morality. Hence, morality affects utilities. In a deeper sense for professional economists, we may note that the relevance of this point is related to the fact that not all interpersonal effects/relationships are negotiated/effected only through market exchange; there are some direct and subtle effects beyond monetary transaction. In addition, morality (or social capital like trust more generally) may also contribute to individual utilities through its contribution to cooperation and economic growth (James 2015, Tabellini 2008, 2010). Similarly, other possible indirect effects may be allowed for.

It may however be argued that morality may affect utilities only through affecting activities, especially if the latter term is defined widely. For simplicity, we are using an atemporal model typical of most economic (especially welfare-related) analysis. However, the real world is on-going. Thus, the morality this period may affect activities and hence utilities in the future periods. Allowing morality to possibly affect utilities independently of its effects on activities this period may thus be a simple way of allowing for its time-delayed effects. Moreover, allowing for its effects only through activities does not affect the validity of our propositions below, as will become clearer later.

Axiom 3: The prevailing morality may be affected by the activities of individuals in the society. The compellingness of this axiom is also obvious, especially since 'activities' may include writing/doing media articles/interviews, engaging in political persuasion, teaching students/children including by doing, etc. Some influences must be possible. As the direction of influence is not specified, the axiom is uncontroversial.

Axiom 4: Each individual in the society maximizes utility subject to a budget and a time constraint. 
Though psychologists and behavioral economists have shown that individuals may deviate from perfect rationality of utility maximization, such deviations are not the focus of this paper. We thus simplify matters by using the simplification of traditional analysis here.

Axiom 5: Each individual is small enough in comparison to the whole society that she takes the aggregate/average variables in the whole society as beyond her control or ignores her negligible effects on the aggregate/average variables.

Admittedly, some monopolistic power for firms may exist and similarly some influences of some individuals on selected others (e.g. family members and friends) must exist. However, these are not the focus of this paper and are abstracted away for simplicity and to concentrate on the overall picture.

Under the axioms above, we may write the utility/welfare of individual $i$ as

$$
U^{i}=U^{i}\left(x^{i}{ }_{1}, \ldots, x_{n}^{i}, X_{1}, \ldots, X_{n}, M\right) \text { for } i=1, \ldots, I
$$

where $\mathrm{x}_{\mathrm{j}}^{\mathrm{i}}$ is the activity levels (i.e. in excess of the original endowed amount if viewed as the amount of excess demand) for all relevant activities [subsuming economic and non-economic] $\mathrm{j}$ by individual $\mathrm{i}, \mathrm{X}_{\mathrm{j}}$ is the total/average amount/degree of activity $\mathrm{j}$ in the society/economy. Under our simplification of a given set of I individuals, we do not have to distinguish the total from the average amount. Axiom 1 actually allows for the possible differential effects of activities of different individuals. In (2), we simplify by just allowing for the aggregate values of activities. Similarly, only the general level of morality $\mathrm{M}$ is taken into account for simplicity. From Axiom 3 , M may be a function of $X_{1}, \ldots, X_{n}$ plus some exogenous factors which we hold constant and thus ignore.

$$
\mathrm{M}=\mathrm{M}\left(\mathrm{X}_{1}, \ldots, \mathrm{X}_{\mathrm{n}}\right)
$$

From Axioms 4 and 5 , each individual i chooses $\left(\mathrm{x}^{\mathrm{i}}, \ldots, \mathrm{x}_{\mathrm{n}}^{\mathrm{i}}\right)$ to maximize $\mathrm{U}^{\mathrm{i}}$ subject to both a budget and a time constraint, taking aggregate variables $X_{1}, \ldots, X_{n}, M$ as beyond her control. The budget constraint is

$$
\sum_{j} \mathrm{p}_{\mathrm{j}} \mathrm{x}_{\mathrm{j}}^{\mathrm{i}}=0
$$

where $p_{j}$ is the price of the economic component of the activity $j$, and $x_{j}^{i}$ is the excess demand of individual i for the relevant economic components $\mathrm{j}$. Note that some of the x's may be negative, signifying negative excess demand or positive excess supply such as for labor services.

Note that some of the p's may be zero [economically free goods/activities] and some may be effectively infinite [illegal or physically impossible activities]. 
The time constraint for each individual is stated implicitly as

$F^{i}\left(x_{1}^{i}, \ldots, x_{n}^{i}\right)=0 ; i=1, \ldots$, I.

The first-order conditions for maximization are:

$$
U_{j}^{i}=\lambda^{i} p_{j}+\mu^{i} F_{j}^{i} j=1, \ldots, n ; i=1, \ldots, I .
$$

where $\mathrm{U}_{\mathrm{j}}^{\mathrm{i}} \equiv \partial \mathrm{U}^{\mathrm{i}} / \partial \mathrm{x}_{\mathrm{j}}^{\mathrm{i}}, \mathrm{F}_{\mathrm{j}}^{\mathrm{i}} \equiv \partial \mathrm{F}^{\mathrm{i}} / \partial \mathrm{x}_{\mathrm{j}}^{\mathrm{i}}$ and $\lambda^{\mathrm{i}}$ and $\mu^{\mathrm{i}}$ are the respective Lagrangean multipliers.

On the other hand, the condition for Pareto-optimality or social optimality may be obtained by the maximization of a Paretian SWF (Eq. 1 above). The individual time constraints in (5) still apply for the society's maximization problem. However, instead of individual budget constraints, the society faces a production possibility constraint

$$
\mathrm{G}\left(\mathrm{X}_{1}, \ldots, \mathrm{X}_{\mathrm{n}}\right)=0
$$

Where $\mathrm{X}_{\mathrm{j}} \equiv \sum_{\mathrm{j}} \mathrm{X}_{\mathrm{j}}^{\mathrm{i}}$ is the total amount of activity $\mathrm{j}$ of the whole society.

The first-order conditions are

$$
W_{i}\left(U_{j}^{i}+U^{i}{ }_{j j}+U_{M}^{i} M_{j}\right)=\lambda G_{j}+\mu^{i} F_{j} ; j=1, \ldots n ; i=1, \ldots, I .
$$

where $\mathrm{W}_{\mathrm{i}} \equiv \partial \mathrm{W} / \partial \mathrm{U}^{\mathrm{i}}, \mathrm{U}^{\mathrm{i}} \mathrm{Xj}_{\mathrm{j}} \equiv \partial \mathrm{U} / \partial \mathrm{X}_{\mathrm{j}}, \mathrm{U}_{\mathrm{M}}^{\mathrm{i}} \equiv \partial \mathrm{U}^{\mathrm{i}} / \partial \mathrm{M}, \mathrm{M}_{\mathrm{j}} \equiv \partial \mathrm{M} / \partial \mathrm{X}_{\mathrm{j}}$.

In a market economy with perfect competition and no external effects, the price of each good faced by the individual equals its marginal cost in production, and the price ratio for any pair of goods equals the marginal rate of substitution for any consuming individuals, which also equals the marginal rate of transformation. Comparing (8) with (6), we note that, for any particular activity $\mathrm{j}$, if $\mathrm{U}^{\mathrm{i}}{ }_{\mathrm{Xj}}=0$ for all $\mathrm{i}$ (i.e. no aggregate or external effects) and either $\mathrm{U}_{\mathrm{M}}^{\mathrm{i}}=0$ for all $i$, and/or $M_{j}=0$, it may be regarded as a private activity affecting only the utility of the individual taking it. If all activities are private in this sense, then (8) may be collapsed into (6) by making $p_{j} / p_{k}=G_{j} / G_{k}$ for all $j, k$ and rewriting in proportionate terms of ratios. This is so under perfect competition for a market economy without distortions. This is consistent with the first theorem of welfare economics (which says that a perfectly competitive equilibrium is Pareto optimal under certain conditions including the absence of external effects like pollution). However, when $U^{i}{ }_{x j}+U^{i}{ }_{M} M_{j}$ is significantly different from zero, there may be divergence between the conditions for private optimality and those for social optimality. In terms familiar to economists, this is due to external effects through $\mathrm{U}^{\mathrm{i}} \mathrm{xj}$ and to generalized external effects through $\mathrm{U}^{\mathrm{i}}{ }_{\mathrm{M}} \mathrm{M}_{\mathrm{j}}$. In fact, even just under $\mathrm{U}^{\mathrm{i}}{ }_{\mathrm{Xj}}$, we may include the more traditional external effects like pollution and the generalized external effects like the feeling of repugnance of some individuals against the prevalence of certain goods or activities $X_{j}$. ${ }^{\text {iii }}$ Thus, if for a particular good $j, X_{j}$ 
enters some individual utility functions negatively and that this negative effects are sufficiently large and widespread, it is possible that the prohibition of the market transaction of this good, even if it may decrease consumer and producer surpluses for some participants, may yet be consistent with Pareto and overall social optimality, as well-known by economists.

To facilitate the statement of our propositions below, some clarification of terms used are given here. We use familiar terms like perfect competition and market power the same as their common usage in economics. We define a 'social equilibrium' in a sense broader than the traditional 'general equilibrium' used in economics as the variables involved include not only goods and services produced and consumed but a wider concept of 'activities'. Otherwise, 'equilibrium' is in the same traditional sense of the absence of departure from the position. From this note and the axioms and discussion above, we have, somewhat trivially, Proposition 1 below whose content is well-known from basic economics.

Proposition 1: A social equilibrium may be Pareto-inefficient even in the absence of any monopolistic power (i.e. Axiom 5 holds and the equilibrium is perfectly competitive) if there exist uncorrected real external effects like untaxed pollution. ${ }^{\text {iv }}$

Proof: The validity of the proposition is trivial as is well-known from basic economic analysis. The existence of uncorrected real external effects like pollution may make a perfectly competitive equilibrium Pareto-inefficient. The validity of this proposition is also intuitively obvious to non-economists. If some serious pollutants/emissions may be reduced at small costs to the polluters but if this is not done due to some reasons, the resulting situation may be inefficient in the sense of having too much pollution. The additional consideration of some 'non-economic' factors like morality does not change the validity of this obvious result, except in the trivial knife-edge case of perfect offsetting of different opposite effects from sheer chance.

Proposition 2: A social equilibrium may be Pareto-inefficient even in the absence of any monopolistic power (i.e. Axiom 5 holds and the equilibrium is perfectly competitive) and uncorrected real external effects like untaxed pollution, if uncorrected generalized external effects exist.

Proof: Given the validity of Proposition 1, Proposition 2 is established by analogy to Proposition 1. Even in the absence of monopoly power, a social equilibrium may be inefficient if some external-cost generating activities like pollution exist and not offset by some measures like 
taxes and regulations, as stated in Proposition 1. Analogously, even in the absence of these uncorrected real external effects like untaxed pollution, a social equilibrium may be inefficient if uncorrected generalized external effects exist. From Axioms 1 and 2, the utility level of a non-secluded individual may be affected by the activities of other individuals and the prevailing morality. Thus, just like excessive/unchecked pollution may cause inefficiency under Proposition 1, the existence of activities that decrease the utility levels of others and through the prevailing morality may also adversely affect others. In maximizing their own utility levels, individuals may thus carry out such activities to excessive levels if unchecked by some counter measures like taxes or regulations. Thus, Proposition 2 must also be true.

Remark 1: The validity of Proposition 1 does not mean that all activities generating some real external costs like pollution must be taxed or regulated. For those with trivial effects, the administrative costs of taxation or regulation may be more than the efficiency gains achieved. In addition, there may also be indirect costs of having too much government intervention. Similarly, the validity of Proposition 2 does not mean that the government has to be the savior of morality and police all activities that may adversely affect others and the general morality. The direct and indirect costs of excessive paternalism may far outweigh its positive effects if any. Nevertheless, both Propositions 1 and 2 remain valid. In considering measures that may address the inefficiencies stated in these propositions, we have to consider both the positive and side effects of the measures which are beyond the scope of Propositions 1 and 2 themselves.

Proposition 3: In general, a conceptual/theoretical analysis without empirical evidence is insufficient to establish whether a certain expansion of the market (or some other policy or social change) is desirable or undesirable according to a Paretian SWF, even in the absence of ignorance, imperfect information and irrationality and in the absence of traditional real external effects like pollution.

Proof: Consider a certain market expansion A to some area/scope not available for market transaction before. [For concreteness, one may think of the lifting of a ban on the importation of some good or the legalization of kidney sale.] In the absence of ignorance, imperfect information and irrationality and in the absence of traditional real external effects like pollution, simple economic analysis shows that parties to the newly created market 
benefits from the additional exchanges. This is amply shown in the literature on the efficiency of free international trade. However, in our expanded model, the increase in economic surpluses through the added exchanges may be more than offset by the nontraditional external effects including repugnance effects $\left(\mathrm{U}^{\mathrm{i}} \mathrm{xj}\right.$ may be sufficiently negative for some $\mathrm{i}$ and $\mathrm{j})$ and intrinsic motivation and/or morality-reduction effects $\left(\mathrm{M}_{\mathrm{j}}\right)$ may be sufficiently negative for some $\mathrm{j}$.

Remark 2: For the case of free international trade in traditional goods and services, it is generally assumed by economists and accepted by most communitarians that the relevant repugnant effects and crowding-out (of intrinsic motivation and morality) effects are negligible if not non-existent. Given this additional empirical assumption/condition/evidence, then a case for free trade may be made and regarded as acceptable. But evidently, some empirical support in the form of either formal evidence, explicit or implicit assumption, or tacit agreement, is needed. To see this more clearly, consider the case of the legalization of kidney sale. With the exception of Iran, all countries ban kidney sale. One of the reasons for this ban is that many people feel repugnant (e.g. Roth 2007, Elías 2015) by the legal transaction in human organs. One may argue that, despite this repugnance, kidney sale should be legalized as the enormous benefits of saving lives should more than offset such feelings of repugnance even by a large number of individuals. However, this is again a form of empirical support, either with solid evidence or by intelligent guess. The absence of a general result regarding, for example, the desirability of market expansion or some other social change, does not mean that no analysis is possible; just that some support from the empirical side regarding the likely signs and sizes of the different effects involved are, in general, needed. For one thing, in contrast to the large literature (since at least Titmuss 1970) on the crowding out of intrinsic motivation and morality regarding for example the payment for blood and others, we also have the opposite results including the lack of crowding out (Bowles \& Polania-Reyes 2012, Chetty, et al. 2014, Gordon et al. 2015), crowing-in effects (e.g. Berggren and Nilsson 2013 and Prasad 2012 on the point that economic freedom fosters tolerance and reduces violent crime; Zak 2011 on the morality-strengthening effects of markets; Goette et al. 2010 for a survey), and the long-standing doux-commence thesis on the civilizing effects of market relations (from Charles-Louis de Montesquieu, Adam Smith, and Thomas Paine to Albert Hirschman, 1982, 
2013). In addition, some arguments showing crowding out may in fact be based on the antimarket sentiment of the authors, as shown in the appendix.

Proposition 4: In judging the likely signs and sizes of the different effects involved in the desirability of a policy or social change, in general, long-term effects as well as current effects should be taken into account.

Illustration: The proposition is stated in general terms and is obviously true; just an illustration is sufficient. Consider the case of the legalization of kidney sale. Despite the enormous benefits of saving lives, it is possible (need not be likely) that legalization may lead to significant feelings of repugnance by so many people that the current benefits are overwhelmed by current costs. [For simplicity, ignore possible other benefits and costs.] However, it may also be possible (if not likely) that, as people get used to legal transactions in kidneys, the feeling of repugnance fades into insignificance over time, making the longterm effects dominated by the benefits of saving lives. That this fading is highly likely is further supported by the next proposition.

Proposition 5: The objection (including feelings of repugnance) to the expansion of the market is likely to decrease over time as people become accustomed to the transaction and as the society becomes more advanced in the degree of division of labour (and specialization), education (especially with more understanding of basic economics) and liberal thinking.

Demonstration: Since this proposition is moderately stated as only being 'likely', its validity may be demonstrated by looking at some historical and current evidence. At the time of Adam Smith (undisputed father of economics), people viewed selling one's service of singing in the public as a 'discredit' and Smith cited this to explain the higher pay needed (Smith, 1776/1982, p.209). We now not only regard singing in public as acceptable but as honorable.

Similarly, when life insurance was first introduced in the $19^{\text {th }}$ century in the U.S., many people regarded it as an 'unnacceptable gamble against God' (Taylor 2014). People admonished, 'You want to set a price on your life, and then place a bet on your date of death?' Now, virtually everyone regards taking life insurance as not only perfectly acceptable but a very prudent measure. As noted by Kessler \& Roth (2014, p. 426), 'repugnant transactions have a long and varied history that changes in time and place (e.g., charging interest on loans, indentured servitude, selling horsemeat for human consumption, 
and same-sex marriage all have been repugnant transactions in some times and places and not in others)'. A representative sample survey of Americans conducted by Leider and Roth (2010) also suggests that disapproval of kidney sales correlates with other socially conservative attitudes. Perhaps we should learn to be more liberal and be less dogmatic?

Elías et al. (2015) show that cases against organ sale are much affected by the lack of relevant information. 'The estimated approval rate for organ payments increased from a baseline of 51.8 percent to 71.3 percent when information was provided-a 19.5 percentage point increase ( $<$ 0.01), or about 38 percent of the baseline’ [p.363]. (See also Heath 2012).

As Hansmann (1989, p.73) argued long ago, 'if society is not willing to give the poor sufficient assets so that they are not inclined to sell a kidney, then society should not refuse to let them sell one of the few assets they have. ... And, after all, society does not prevent the poor from accepting pay for jobs such as coal mining and meat packing that carry substantial risk of injury or death. Why should kidneys be different?' Though Hansmann also discussed some possible reasons for some differences, he found them not to be strong enough to make us banning kidney sale.

\section{Applications}

Our analysis above does not provide a definite conclusion regarding the desirability of a certain policy or social change such as the expansion of the market beyond its traditional confines. However, it indicates certain pathways that should be taken into account and it reaches some general conclusions that may provide some guides in the specific analysis of particular changes. In the following sub-section, we examine the desirability of paying for blood donation and allowing kidney sale with the help of our analysis above, partly for its own sake and partly as illustrative. In the subsection following that, we examine the complicated issues involved on the desirability of immigration.

\subsection{Market Expansion: Blood vs. Kidney}

If we use a narrow economic framework, we may conclude that letting the price rise (including from zero) in the presence of shortage (which is true for both blood and kidneys) is efficient/desirable, as is done in the teaching of basic economics on the inefficiency of price controls. However, from the last section (Propositions 2 and 3 in particular), we cannot conclude generally in favour of freer market in blood and kidney, even in the absence of ignorance, 
imperfect information and irrationality and in the absence of traditional real external effects like pollution. This is so since there may exist generalized external effects like the feeling of repugnance and the crowding out of intrinsic motivation and morality (including through $\mathrm{U}_{\mathrm{M}}^{\mathrm{i}}$ $\mathrm{M}_{\mathrm{j}}$ ). This does not mean that we can say nothing; rather, just that we need to examine the case specifically and evaluate the various effects before we may say whether some conclusions are possible. Though a more definitive conclusion may require further empirical studies (which are beyond the scope of this paper), some tentative analysis is possible.

In many countries, blood is supplied mainly by voluntary donation with only symbolic recognition and minor in-kind rewards instead of by monetary payment. Though some shortage still occurs from time to time, this is usually solved by donation campaigns. An economist may think that using the price mechanism is more effective not only in eliciting more supply but also more efficient in generating more economic surpluses, without using too much resources in donation campaigns. While this may be true for most goods and services, the case of blood supply is more complicated. First, using monetary payment for blood may crowd out voluntary donation and attract unsafe donors, as analyzed from Titmuss (1971), through Frey \& Oberholzer-Gee 1997, to Costa-Font, et al. (2013) ${ }^{\mathrm{v}}$. Secondly, people derive the warm-glow effect in making unpaid donation and the widespread use of monetary payment for donation may decrease this warm-glow effects. Instead of saving lives, it is now only something worth perhaps a hundred dollars. Thus, if voluntary donation does not result in too serious a shortage leading to too many life-threatening situations, keeping donation free of monetary payment has some important advantages. In fact, this would likely be the case if a lesson on the basic knowledge of blood donation is introduced at high schools, as argued below.

While excessive blood donation may be undesirable, regular donation is in fact beneficial to the donors. This is so because, as hunters-gatherers, we faced frequent blood loss in our daily life. Thus, we are programmed to replenish our frequent blood loss. However, modern living makes blood loss almost non-existent, especially for men. This unhealthy situation is improved by undertaking frequent but not excessive blood donation (e.g. Meyers et al. 2002, Salonen et al. 1998). Thus, an adequate education of this simple point will likely make voluntary donation more than adequate to ensure adequate blood supply in most countries. This is particularly relevant for a culture like the Chinese, though not just confined to China. The traditional belief in China is that any part of the body, including even hair and skin, not to mention blood, is from the 
parents and should not be discarded (as evidenced in, e.g. the widely-read historical novel The Three Kingdoms). Another belief is that blood is the essence of life and losing blood will weaken the body significantly (Zaller et al. 2005, Tison et al. 2007, Lownik et al. 2012). This half-truth ignores the point that our body is programmed to replenish blood loss. If we have a lesson at the high school level on the biological basis of healthy blood donation, voluntary donation will likely increase ten times or more in China without payment. If we could have adequate and safer blood supply with just some simple education, there is no need to shift to a system of using financial payment to induce blood donation. Voluntary and free donation may be kept not only as an effective way of generating blood supply but also as something promoting altruism, morality, and communitarianism.

The case of kidneys is altogether a different story. While our body is programmed to regenerate blood, it cannot regrow another kidney after transplantation. Despite the fact that one can healthily live on one kidney, kidney sale (and purchase) is illegal in all countries except Iran. The legal but regulated market there has avoided many problems associated with the inadequate black-market kidney trade and all other systems used in other countries have failed to solve the worsening kidney transplant queues, with many dying while waiting (Lim 2008; see also the website of the Organ Procurement and Transplantation Network). Under legal kidney sale, it is true that some ex-post regrets exist (Cohen 2014). However, this is true for most if not all other legal or illegal transactions and decisions. The existence of substantial regrets may warrant more pre-sale counseling, but no system can ensure the complete absence of regrets. Obviously, the costs of some regrets may be overwhelmed by the large surpluses for both the selling and purchasing sides.

One may cite cases in China where someone wanted to sell his kidney just to finance the buying of an iphone to show the silliness of the transaction, at least of the kidney-selling side. However, this silliness was a problem of that particular seller, not that of the legality of kidney sale. In fact, kidney sale is illegal in China. Actually, with legal status and appropriate regulation, the tragic case of an illegal kidney sale resulting in serious injuries (see endnote to this paragraph) would be most likely prevented. Such cases in fact illustrate the serious problems of illegality, not of legalization. Legal prohibition does not stop transaction and trafficking but creates many problems (Hippen 2005). Also, one may also cite the case of a person in Tianjin in 2003 who, in order to buy a mobile phone, borrowed and skipped meals to save money. He succeeded in 
buying a mobile phone, but ended up in the hospital while cycling to show off his newly acquired phone to dozens of friends, fainting in the process partly due to under-nourishment. The purchase was certainly silly, but no one suggested banning mobile phones. Similarly, one cannot reject the legality of kidney sale based on some silly transactions. ${ }^{\mathrm{vi}}$

As allowed in the analysis of the previous section, one may argue against the legalization of kidney sale on the ground of generalized external costs including the feeling of repugnance against such markets (e.g. Roth 2007, Kessler \& Roth 2014). However, for kidney transplant needed to save lives, it seems that the feeling of sympathy, instead of repugnance, should be more appropriate for both the seller who is desperate enough to sell one of her kidneys and the buyer who is desperate to save her life or that of her loved one. Even if some substantial repugnance remains, it probably fades into insignificance in comparison to the enormous gains of saving lives, especially if the long-term perspective is taken, as required by Proposition 4 above, and as further strengthened by Proposition 5. On the other hand, the possible concern regarding the fairness or equality concern of allowing such market transactions as kidney sale, one may invoke the principle of treating a dollar as a dollar on specific issues, leaving the objective of reducing inequality to the general tax/transfer system as being more efficient (Pareto-optimal) even taking account of the disincentive effects of the tax/transfer system (Ng 1984). (The present author is not against the promotion of more equality, just in favour of using more efficient ways for such promotion so that more equality may be achieved at any given amount of efficiency costs. This does not preclude that certain measures may promote both efficiency and equality.) This is so because the specific equality-oriented policies also have disincentive effects, though popularly ignored. Obviously, further studies on the likely strengths of the various effects may be desirable to further support our case for keeping voluntary blood donation but for legalizing kidney sale may be desirable, but this is beyond the scope of this paper (see Ng \& Wang 2016 for further arguments).

\subsection{Immigration}

Let us now consider the desirability of allowing immigration into a country/city, from the viewpoints of the existing residents/people and from a wider perspective, mainly to illustrate the many different issues involved that have to be taken into account, rather than to provide a conclusive answer. 
If we take a narrow economic perspective, one may be prone to argue that, unless the immigrant takes with her an enormous amount of capital or skill, allowing an additional person/family to share the given limited natural resources of the country will reduce per-capita resources and per-capita income and hence undesirable for the current local/domestic people. Even on its own ground of a narrowly economic perspective and even if all external effects (traditional and generalized), ignorance, and morality issues are all ignored, this simple or even naïve case against immigration is invalid, even ignoring complications such as increasing returns (to scale, to scope, to specialization at different levels).

To see this, consider the simple textbook case of constant returns to scale, perfect competition, no external effects, no-government, and payment to factors of production in accordance to marginal productivity. For simplicity, consider the immigration of unskilled labor without capital or any other economic ability like entrepreneurship, a case probably regarded as least favorable. For simplicity and concreteness, but without real loss of generality for this simplified case, suppose that the production function of this relevant economy is $\mathrm{Y}=$ $\mathrm{L}^{1 / 2} \mathrm{~K}^{1 / 2}$ where $\mathrm{L}$ is unskilled labor and $\mathrm{K}$ is the composite of all other factors which we hold constant at $\mathrm{K}=100$. Before immigration, $\mathrm{L}=100, \mathrm{Y}=100$, and with the normalization of one person one unit of labor supply, the per-capita income is one, with, on average, each person earning half of her unit of income from $\mathrm{L}$ and another half from $\mathrm{K}$, and with the price/wage-rate for $\mathrm{L}$ and $\mathrm{K}$ (being equal to $\partial \mathrm{Y} / \partial \mathrm{L}$ and $\partial \mathrm{Y} / \partial \mathrm{K}$ respectively) both at $1 / 2$. Now introduce the immigration of 10 persons each with one unit of $\mathrm{L}$ but no $\mathrm{K}$. The total output after immigration increases from 100 to approximately 104.9, but the per-capita income decreases from 1 to approximately 0.9535. Have the original 100 local residents been made worse off economically? No! The marginal product of $\mathrm{L}$ decreases from 0.5 to 0.47673 , but the marginal product of $\mathrm{K}$ increases from 0.5 to 0.5244. For an average local who own one L and one K, her income increases from 1 to 1.0011344 . She actually gains from the immigration. This gain is due to the fact that, even ignoring other possible positive factors like increasing returns, the immigration of a particular factor decreases the marginal product of this factor but increases the marginal products of complementary factors by more. Thus, the original residents as a whole group actually gain economically from immigration. This is so despite from the possible decrease in per-capita income. The decrease in per-capita income applies to all people including the new 
immigrants. Focusing on the per-capita income hides the fact that local residents may gain despite a fall in per-capita income calculated to include the new immigrants.

This gain may also be seen by the point that the 10 immigrants earns the marginal product of $\mathrm{L}$ (MPL) when $\mathrm{L}=110$, but their total contribution to production equals the integration of MPL from $\mathrm{L}=100$ to $\mathrm{L}=110$. With diminishing marginal productivity of $\mathrm{L}$ (as $\mathrm{K}$ is held constant and constant returns to scale is assumed), MPL is higher at $\mathrm{L}=100$ than at $\mathrm{L}=110$. Thus, the total contribution to production of these 10 immigrants is higher than their total earnings. Their contribution net of their incomes must thus be positive. The original 100 residents must benefit as a group. If these 100 residents do not own the same amount of $\mathrm{L}$ and $\mathrm{K}$, those mainly or exclusively only own L may lose, but those mainly own K must gain by more. Local residents benefit from immigration even in this simple model with no increasing returns and public goods. The recognition of these latter factors makes the gain much larger, and may lead to an increase in per-capita income (even calculated to include the new immigrants). In terms of magnitude, it is likely that the cost-sharing in the provision of public goods like defence, research, and broadcasting is probably much more important than the gain identified above. However, our simple model above also does not allow for such negative factors like congestion and pollution. Does the introduction of these negative factors make local residents worse off with immigration? As shown by Clarke \& Ng (1993), if external costs like congestion and pollution are taxed according to their marginal damages, even if immigration worsens the situation of congestion and pollution, local residents still benefit from the larger population size. However, this positive result does not apply to immigrants who rely on government subsidies that cannot be offset by their future tax payment.

The concern about congestion and pollution is particularly likely to lead to incorrect antiimmigration thinking. For example, when people encounter serious congestion, they would likely think: 'If the number of cars on the road (or passengers in the carriages) were halved, how nice it would be!' Thus, people tend to blame congestion and pollution on population size. A more complete analysis should consider the following. Given the amount of per capita investment and taxes, if the population size and number of cars were halved, the width of the roads would also roughly be halved. Congestion would likely increase as a result. With fewer people, public transportation would have fewer routes, and the frequency of trains and buses would be lower. For example, I live inside the NTU campus and have had occasions to catch the 
179 bus. Once, just before reaching the bus-stop, I saw two 179's passing. I thought I had to wait at least 20 minutes but the next 179 came in less than two minutes. In contrast, 5 decades ago (I was a student in the same campus) when Singapore had a population of less than 1/3 its current size, if one missed a bus going out of the campus, one had to wait a full half-an-hour. This is a concrete example of an advantage of a larger population that most people overlook. It is odd that few people takes into account the fact that transportation is much more convenient in densely populated cities like Tokyo, London, Shanghai, and Singapore than in the country side or even in smaller cities. Though a larger population leads to larger requirements and challenges, it also provides much more resources. With adequate catching up in the provision of relevant infrastructure, a larger population typically provides net benefits, especially to the original people. For the same job at the same salary, most people prefer to work in a bigger city, despite having to pay more for housing. As often reported, medical practices in small towns have difficulties attracting medical doctors to work there despite offering the doubled amount of salary. On balance, the advantages of a larger population typically more than offset the costs, contrary to the popular opposite belief.

There is a possible distributional consideration not covered above. Thus, in the simple model above, while local residents as a group gain, owners of L may lose. If they belong to the lowerincome groups, inequality may increase. The loss of the poor of $\$ \mathrm{X}$ may more than offset the gain of the rich of $\$ 2 \mathrm{X}$ in welfare terms. However, as noted at the end of the previous subsection, it is more efficient to focus on efficiency on each specific issue. Moreover, though the immigration of unskilled workers into country A may make the distribution of income within country A less equal, it actually makes distribution more equal globally.

Our discussion of the economic effects of immigration, though throwing some lights, is inadequate to answer the general question on the desirability of immigration, even just from the viewpoint of local residents only. This is so because there may be negative non-economic effects that could more than offset the positive economic effects. Obviously, if immigration leads to serious social disharmony or even outright conflict, all people involved may be made seriously worse off overall, even if the per-capita income increases significantly. In addition to this wellknown social harmony issue, our analysis in the previous section also suggests that more subtle effects through generalized external effects including the effects on morality may also have to be taken into account. Of course, these wider effects of immigration may either be positive or 
negative. All these suggest that an adequate analysis of a public policy or social change is likely to involve a host of relevant factors and calls for a multidisciplinary study. Though this is beyond the scope of this paper, the framework provided in this paper may give some guides, though it certainly falls short of a full analysis.

\subsection{Concluding Remarks}

Public policy issues are very complicated and typically involve many factors including economic and beyond, including fairness, harmony, relationships, networks, altruism, morality, etc. Nevertheless, as ultimately it is individuals in the society that feel the effects of social events or changes, the traditional economic analysis focusing on individual utilities and social welfare may be extended to incorporate these wider effects. This paper provides a modest attempt at such an extension with some general propositions that may provide some guides to the analysis of wider costs and benefits of specific social changes and/or public policies. While this extended framework certainly does not capture all complications involved, it may provide some useful extensions in some respects. For example, applying the general results to examine the desirability of extending the market, we reach the tentative conclusion that keeping blood donation voluntary without financial payment is likely desirable, especially with adequate education on the usefulness of donation to the donors; on the other hand, legalizing kidney sales may be desirable, though certain regulations and more studies may be needed. Further extensions and applications await future research.

\section{Appendix. The Anti-Market Sentiment}

Falk and Szech (2013) published a paper in Science, a top-ranked scholarly journal, claiming to show that 'markets erode moral values'. Their experiments are very simple. In treatment 1 , a single individual decides whether to get 10 euros or save a mouse from being killed. In treatment 2, two persons bargain to share 20 euros, and in treatment 3, more persons are involved. Significantly lower proportions of people under treatment 1 opted to receive the money than the other treatments. Falk and Szech interpret the situations in treatments 2 and 3 involving bargaining as more market-like and thus conclude that 'markets erode moral values'. This conclusion is clearly unwarranted from their experiments. 
Breyer and Weimann (2015) have a more comprehensive criticism, focusing of the statistical aspects. Here, I want to focus on two simple common-sense considerations that make the claim of morality-erosion of markets of Falk and Szech based on their experiments completely invalid.

In treatment 1, the individual concerned is fully responsible for the mouse being killed if she accepts the 10 euros. In the other two treatments, she is only one of two or more individuals involved. Clearly, this is going to have a huge difference in the perception of responsibility. It is thus not surprising, even fully to be expected, that if there are no significant other effects, we will likely have higher proportions of decisions to accept the money instead of saving the mice under treatments 2 and 3. Thus, the experimental results of Falk and Szech cannot be accepted as evidence showing the morality-erosion of markets at all. The responsibility-dilution effect itself is sufficient in negating their conclusion. The morality-erosion effects of markets may or may not exist, but they have not been demonstrated by their experiments.

We may in fact go further than this pure responsibility-dilution effect for the difference between treatment 1 and other treatments. In treatment 1, the individual knows that she can save the life of the mouse by refusing to take the money. In other treatments, there are other individuals involved. Thus, even if the individual concerned prefers not to take the money (to save the mouse), she has other individuals to consider. She may think thus: 'Since these other individuals may gain some money by letting the mouse die, I should not just do as I please (saving the mouse)'. This consideration may again reinforce the responsibility-dilution effect to increase the proportions of taking the money under treatments 2 and 3.

Both this consideration-of-others and the several points discussed by Breyer and Weimann may be somewhat subtle and not easily seen. However, the responsibility-dilution effect is clear and conspicuous. In fact, Falk and Szech (2015, p.708) themselves, commenting on treatment 2, note that 'it takes two people who agree on trading to complete a trade, implying that responsibility and feelings of guilt may be shared and thus diminished'. Despite this recognition, they draw the invalid conclusion. This is quite remarkable. Equally if not more remarkable is the fact that a paper that draws such an obviously invalid conclusion passed through the screening processes of the referees and editors of one of a few top journals in the whole academic world! Apart from the fact that we are all human, there are likely to be some background factors that 
facilitate such outcomes. A likely factor is the anti-market sentiment of the general public, including many scholars.

The anti-market sentiment is fostered by a number of factors, including the following. First, though the use of markets has led to tremendous increases in wealth, it has also resulted in high degrees of inequality in the distribution of incomes and wealth. From both nature and nurture, most of us have a preference for equality. We thus hate or at least dislike the inequality outcomes partly fostered by the market. Reinforcing this dislike is the fact that the manifestation of inequality, especially in the forms of extreme richness and poverty, are very conspicuous and often reported widely. On the other hand, the market's contributions to efficiency and growth are less conspicuous or are taken for granted, at least are much less reported by the mass media. This perception bias is somewhat similar to that causing the anti-immigration bias. For example, the filling of jobs that could have been taken by locals but by immigrants instead is conspicuous; the creation of more jobs by immigrants or a larger population is indirect and not conspicuous. For details, see the discussion of many such fallacies in Ng (2011).

Secondly, the incentives for monetary gains are large and may lead to both huge positive achievements that also benefit others and terrible negative activities including tax evasion, corruption, robberies, kidnappings, murders, wars, etc. Again, people tend to focus more on the conspicuous, and widely reported negative effects and largely ignore the positive effects. This focus leads people to have a negative views on money and markets, and in fact all things material.

The anti-market sentiment was reinforced in recent years by a number of factors. First, the global financial crisis around 2008, including the role played by the money grabbers in it, intensified the sentiment. Secondly, the increasing degrees of inequality in the distribution of incomes and wealth in the last four decades or so (on which see Piketty 2014, but see also McCloskey 2014, Facchini \& Couvreur 2015, and Ng 2015 for some qualifications on the analysis) has become more noticeable and more salient in recent years due to the slower growth after the global financial crisis.

Scholars are also members of the general public. The anti-market sentiment thus also affects them, particularly so for those not well versed in the intricate functioning of the market mechanism. (Those anti-market scholars who believe that they are in fact so well versed should see whether they have taken account of the argument for treating a dollar as a dollar in specific issues discussed in Section 2 in the text above.) When an anti-market conclusion, such as the one 
that markets erode moral values, appears to be obtainable, they thus grab on it without much careful reasoning. This applies equally to authors, referees, and editors, even of top journals. We should thus be very cautious of such anti-market conclusions.

\section{References}

ANDERSON, Elizabeth (1993). Value in Ethics and Economics. Cambridge: Harvard University Press.

BECKER, Gary S. (1957/1971). The Economics of Discrimination. Chicago: University of Chicago Press.

BECKER, Gary S. (1978). The Economic Approach to Human Behaviour, Chicago: University of Chicago Press.

BECKER, Gary S. (1992). The economic way of looking at life, Nobel Lecture.

BENJAMIN, Daniel J., HEFFETZ, Ori, KIMBALL, Miles S. \& REES-JONES, Alex (2012). What do you think would make you happier? What do you think you would choose? American Economic Review, 102(5): 2083-2110.

BERGGREN, Niclas and NILSSON, Therese (2013). Does economic freedom foster tolerance? Kyklos. 66: 177-207.

BOWLES, S., \& POLANIA-REYES, S. (2012). Economic incentives and social preferences: Substitutes or complements? Journal of Economic Literature, 50(2): 368-425.

BREYER, F., \& WEIMANN, J. (2015). Of morals, markets and mice: Be careful drawing policy conclusions from experimental findings! European Journal of Political Economy, 40: 387390.

BUCHANAN, James M. \& TULLOCK, Gordon (1962), The Calculus of Consent, Ann Arbor: University of Michigan Press.

CHETTY, R., SAEZ, E., \& SÁNDOR, L. (2014). What policies increase prosocial behavior? An experiment with referees at the Journal of Public Economics. Journal of Economic Perspectives, 28(3): 169-88.

CLARKE, Harry \& NG, Yew-Kwang (1993). Immigration and economic welfare: Resource and environmental aspects”, Economic Record, 69(206): 259-273.

COASE, Ronal H. (1978). Economics and contiguous disciplines. Journal of Legal Studies, 7(2): 201-211. 
COHEN, I. Glenn (2014). A fuller picture of organ markets, American Journal of Bioethics. 14: $19-21$.

COSTA-FONT, Joan, JOFRE-BONET, Mireia and YEN, Steven T. (2013). Not all incentives wash out the warm glow: The case of blood donation revisited, Kyklos, 66: 529-551.

DAVIS, John B. (forthcoming). Economics imperialism versus multidisciplinarity, History of Economic Ideas. Available at SSRN.

DOWNS, Anthony (1957). An Economic Theory of Democracy, New York: Harper.

ELÍAS, Julio J. (2015). The role of repugnance in the development of markets: The case of the market for kidneys for transplants. CESinfo.

ELÍAS, Julio J. , LACETERA, Nicola \& MACIS, Mario (2015). Sacred values? The effect of information on attitudes toward payments for human organs, American Economic Review, 2015, 105(5): 361-365. http://dx.doi.org/10.1257/aer.p20151035

FALK, Armin and SZECH, Nora (2013). Morals and markets, Science 340, pp.707-711.

FACCHINI, Francois \& COUVREUR, Stéphane (2015). Inequality: The original economic sin of capitalism? An Evaluation of Thomas Piketty's "Capital in the twenty-first century", European Journal of Political Economy, 39: 281-287.

FINE, Ben (2002). Economic imperialism: A view from the periphery. Review of Radical Political Economics, 34:187-201.

FINE, Ben \& MILONAKIS, Dimitris (2009). From Economics Imperialism to Freakonomics: The Shifting Boundaries between Economics and Other Social Sciences. London: Routledge.

FREY, Bruno S. \& OBERHOLZER-GEE, Felix (1997). The cost of price incentives: An empirical analysis of motivation crowding-out, American Economic Review, 87(4), 746755.

GOETTE, L., STUTZER, A., \& FREY, B. M. (2010). Prosocial motivation and blood donations: a survey of the empirical literature. Transfusion Medicine and Hemotherapy, 37(3), 149154.

GORDON, E. J., PATEL, C. H., SOHN, M. W., HIPPEN, B., \& SHERMAN, L. A. (2015). Does financial compensation for living kidney donation change willingness to donate? American Journal of Transplantation, 15(1), 265-273. 
HANSMANN, Henry (1989). The economics and ethics of markets for human organs. Journal of Health Politics, Policy and Law, 14(1), 57-85.

HEATH, Joseph. (2012). Letting the world in: Empirical approaches to ethics. Ethics Forum, 7(3): 93-107.

HIPPEN, B. E. (2005). In defense of a regulated market in kidneys from living vendors. Journal of Medicine and Philosophy, 30, 593-626.

HIRSCHMAN, Albert O. (1982). Rival interpretations of market society: Civilizing, destructive, or feeble? Journal of Economic Literature, 20(4): 1463-1484.

HIRSCHMAN, Albert O. (2013). The Passions and the Interests: Political Arguments for Capitalism before its Triumph. Princeton University Press.

HIRSHLEIFER, Jack (1985). The expanding domain of economics. American Economic Review, 75(6), 53-68.

JAMES, Harvey S., Jr. (2015). Generalized morality, institutions and economic growth, and the intermediating role of generalized trust, Kyklos, 68(2): 165-196.

KESSLER, Judd B. and ROTH, Alvin E. (2014). Getting more organs for transplantation, American Economic Review, 104(5): 425-430. http://dx.doi.org/10.1257/aer.104.5.425

LAZEAR, Edward (2000). Economic imperialism. Quarterly Journal of Economics, 115(1), 99146.

LEIDER, Stephen, and ROTH, Alvin E. (2010). Kidneys for sale: Who disapproves, and why? American Journal of Transplantation, 10 (5): 1221-27.

LIM, M. K. (2008). Legalization of Organ Trade. Singapore: National University of Singapore.

LOWNIK, E, RILEY, E, KONSTENIUS, T, RILEY, W AND MCCULLOUGH, J (2012). Knowledge, attitudes and practices surveys of blood donation in developing countries, Vox sanguinis. 103: 64-74.

MÄKI, Uskali (2009). Economics imperialism concept and constraints. Philosophy of the Social Sciences, 39(3), 351-380.

MCCLOSKEY, Deirdre N. (2014). Measured, unmeasured, mismeasured, and unjustified pessimism: a review essay of Thomas Piketty's Capital in the twenty-first century, Erasmus Journal for Philosophy and Economics, 7(2): 73-115. 
MEYERS, David G, JENSEN, Kelly C and MENITOVE, Jay E (2002). A historical cohort study of the effect of lowering body iron through blood donation on incident cardiac events, Transfusion. 42: 1135-1139.

MUELLER, Dennis (2003). Public Choice III, Cambridge University Press.

MUELLER, Dennis (2009). Reason, Religion, and Democracy, Cambridge University Press.

NG, Yew-Kwang (1975). Bentham or Bergson? Finite sensibility, utility functions and social welfare functions, Review of Economic Studies, 42(4): 545-569.

NG, Yew-Kwang (1984). Quasi-Pareto social improvements. American Economic Review, 74(5): 1033-1050.

NG, Yew-Kwang (1990). Welfarism and utilitarianism: A rehabilitation. Utilitas, 2(2): 171-193.

NG, Yew-Kwang (1995). Towards welfare biology: Evolutionary economics of animal consciousness and suffering, Biology and Philosophy, 10: 255-285.

NG, Yew-Kwang (1999). Utility, informed preference, or happiness? Social Choice and Welfare, 16(2): 197-216.

NG, Yew-Kwang (2011). Common Mistakes in Economics: By the Public, Students, Economists, and Nobel Laureates, Nova, 2011. Open access.

NG, Yew-Kwang (2013). The Road to Happiness, Shanghai: Fudan University Press.

NG, Yew-Kwang (2015). Is an increasing capital share under capitalism inevitable? European Journal of Political Economy, 38: 82-6.

NG, Yew-Kwang (2016). How welfare biology and commonsense may help to reduce animal suffering, Animal Sentience, 2016, 007.

NG, Yew-Kwang \& WANG, Yan (2016). The proper limits of markets. Typescript.

OLSON, Mancur (1965), The Logic of Collective Action: Public Goods and the Theory of Groups, Cambridge, Mass.: Harvard University Press.

PICOU, Arthur C. (1922). Empty economic boxes: A reply, Economic Journal, 4(2): 458-65.

PIKETTY, Thomas (2014). Capital in the Twenty-First Century, The Belknap Press of Harvard University Press, Cambridge, Massachusetts; London, England.

POLANYI, K. (1944), The Great Transformation, Boston: Beacon Press.

PRASAD, Kislaya (2012). Economic liberalization and violent crime, Journal of Law and Economics, 55(4): 925-48. 
ROTH, Alvin E. (2007). Repugnance as a constraint on markets, Journal of Economic Perspectives. 21: 37-58.

SALONEN, Jukka T, TUOMAINEN, Tomi-Pekka, SALONEN, Riitta, LAKKA, Timo A \& NYYSSONEN, Kristiina (1998). Donation of blood is associated with reduced risk of myocardial infarction: The kuopio ischaemic heart disease risk factor study, American Journal of Epidemiology. 148: 445-451.

SANDEL, Michael (2012). What Money Can't Buy: The Moral Limits of Markets. New York: Farrar, Straus and Giroux.

SANDEL, Michael (2013). Market reasoning as moral reasoning: Why economists should reengage with political philosophy, Journal of Economic Perspectives. 27:121-140.

SATZ, D. (2010). Why Some Things Should Not Be for Sale: The Moral Limits of Markets. Oxford: Oxford University Press.

SLONIM, Robert, WANG, Carmen and GARBARINO, Ellen (2014). The market for blood, Journal of Economic Perspectives. 28: 177-196.

SMITH, Adam (1976/1982). The Wealth of Nations. U.K: Penguin.

STIGLER, George. 1984. Economics-The imperial science? Scandinavian Journal of Economics, 86:301-13.

TABELLINI, Guido (2008). Institutions and culture, Journal of the European Economic Association, 6(2-3): 255-94.

TABELLINI, Guido (2010). Culture and institutions: Economic development in the regions of Europe, Journal of the European Economic Association, 8 (4): 677-716.

TAYLOR, Timothy (2014). Economics and morality, Finance \& Development, 51(2): 34-88.

TISON, Geoffrey H, LIU, Changli, REN, Furong, NELSON, Kenrad and SHAN, Hua (2007). Influences of general and traditional Chinese beliefs on the decision to donate blood among employer-organized and volunteer donors in Beijing, China, Transfusion. 47: 1871-1879.

TITMUSS, Richard M. (1971). The Gift Relationship. London: Allen and Unwin.

ZALLER, Nickolas, NELSON, Konrad E, NESS, Paul, WEN, Guoxing, BAI, X \& SHAN, H (2005). Knowledge, attitude and practice survey regarding blood donation in a northwestern Chinese city, Transfusion Medicine. 15: 277-286.

ZAK, P. J. (2011). Moral markets. Journal of Economic Behavior \& Organization, 77(2): 212233. 
i This explicit concern can be traced back to at least Polanyi (1944) but has intensified in the recent decade or so; e.g. see Satz (2010).

ii Davis' (forthcoming) case against economics imperialism and for multidisciplinarity has some validity, but some of the claims seem excessive, e.g. 'agents were interdependent ... standard optimization analysis was thus meaningless' (p.10). The interdependency may make standard optimization analysis not fully recognizing the interdependency inadequate (and may need supplementation with analysis of such additional complicating factors as external effects, social interaction, institutions, networks, dynamic, etc.), but certainly not meaningless.

iii What we call real vs. generalized external effects correspond roughly to physical vs. psychological external effects of Mueller (2009, pp. 241-3).

iv The word 'real' is added to qualify 'external effects' because pecuniary external effects through the price system do not cause inefficiency under classical conditions. 'Real' also indicates a distinction from 'generalized' or 'psychological' external effects discussed in the text.

${ }^{\mathrm{v}}$ However, see Slonim et al. 2014 for the many complicated factors involved.

${ }^{\text {vi }}$ On the first type of incidents, see http://news.sina.com.cn/o/2015-09-16/docifxhxzxp4388159.shtml and http://news.sohu.com/20120406/n339897086.shtml ; on the second incident, see http://news.enorth.com.cn/system/2003/01/14/000490807.shtml . 